\title{
TRICUSPID INCOMPETENCE IN COR PULMONALE
}

\author{
BY \\ D. VEREL, G. SANDLER, AND S. J. MAZURKIE \\ From the Regional Cardiovascular Unit and Department of Cardiology, United Sheffield Hospitals, Sheffield
}

Received December 4, 1961

In a survey of the Sheffield Region, Stuart-Harris, Twidle, and Clifton (1959) found that cor pulmonale was the commonest cause of heart failure resulting in admission to hospital. The investigation to be described was initiated when a patient in heart failure due to cor pulmonale was found to have a systolic murmur suggesting tricuspid incompetence which radiated down below the diaphragm into the left and right lobes of the liver reaching maximum intensity some 3 inches from the heart. In this patient the murmur remained constant over 13 weeks of bedrest in hospital. The necropsy showed gross cor pulmonale with cardiac cirrhosis but no organic disease of the tricuspid valve.

Tricuspid incompetence has been recognized since early in the last century. In a historical note, Muller and Shillingford (1954) referred to seven descriptions published before 1840 . An early account of a tricuspid valve lesion in which a systolic murmur was audible below the diaphragm may be that of Stokes (1854) who described a patient with a ruptured tricuspid valve in whom a systolic murmur was audible deep to the sternum and "along the course of the aorta." Bramwell (1884) described the murmur of tricuspid incompetence as "soft and blowing; the site of maximum differential intensity is the lower end of the sternum or adjacent costal cartilages; and its direction of propagation upwards and to the right." Subsequent writers have confirmed this description adding that the murmur may be widespread and audible to the apex (Broadbent, 1897; Gibson, 1898; Mackenzie, 1913; White, 1944; Wood, 1956; Levine and Harvey, 1959).

An investigation was therefore undertaken in which patients with cor pulmonale and tricuspid incompetence were assessed clinically and with a phonocardiograph in order to determine the site of maximum intensity of the systolic murmur resulting from tricuspid incompetence. The radiation of the murmur was also investigated in a number of patients with chronic rheumatic carditis and tricuspid incompetence.

\section{Methods}

Patients with tricuspid incompetence usually came in as acute emergencies. A careful note of the radiation of the site of maximum intensity of the murmur was made using a stethoscope and as soon as the patient's condition permitted they were moved to the phonocardiograph room. The site of auscultation and phonocardiography was related in all cases to the xiphisternum. The place at which a phonocardiograph microphone was placed was recorded, for example as "left 2 , up 1," if the point taken was 2 inches to the left of the xiphisternum and 1 inch above it. Standard lead II of the electrocardiogram and a jugular phlebogram were recorded in every case. Two phonocardiograms were also recorded: one acting as a reference was taken from the pulmonary area, the second was placed at the apex and the xiphisternum and at various points round the xiphisternum to determine the point of maximal sound. In comparing records in the same patient 
it was possible to use the record from the pulmonary area to ensure that no major difference had occurred. Records were taken in inspiration and expiration using a 6-channel N.E.P. recording camera.

\section{RESULTS}

Observations were made in 5 patients suffering from cor pulmonale and 7 patients with rheumatic heart disease. In cor pulmonale (Table I) the systolic murmur was best heard below the xiphisternum in 4 patients. In all of these it was audible on both sides, but was best heard to the left in 3 ,

TABLE I

The Site of the Murmur and Radiation in Cor Pulmonale with TRICUSPID INCOMPETENCE

\begin{tabular}{l|c|c}
\hline Name & Loudest area & Next loudest \\
\hline B.McC. & $\mathbf{D}_{1} \mathbf{L}_{2}$ & Xiphisternum \\
J.K. & $\mathbf{D}_{1} \mathbf{L}_{2}$ & Xiphisternum \\
J.S. & $\mathbf{D}_{2} \mathbf{R}_{2}$ & Xiphisternum \\
A.L. & $\mathbf{D}_{1} \mathbf{L}_{2}$ & Xiphisternum \\
J.W. & $\mathbf{U}_{1} \mathbf{L}_{2}$ & Xiphisternum \\
J.G. & Xiphisternum & $\mathbf{U}_{1} \mathbf{L}_{1}$ \\
\hline
\end{tabular}

In this and Table II the point referred to is measured in inches from the xiphisternum, thus, $D_{1} L_{2}$ is one inch below and two inches to the left of the xiphisternum.

and to the right in 1 patient. In 4 of these (B.McC., J.R., J.S., A.L.) a murmur was audible 3 or 4 inches below the xiphisternum and over the area of the liver. Its character did not differ from that in the xiphisternal region. In one patient it was best heard above the xiphisternum and to the left: in this instance the murmur also radiated below the diaphragm to the left and it was less well heard in this region. A typical recording is shown in Fig. 1.

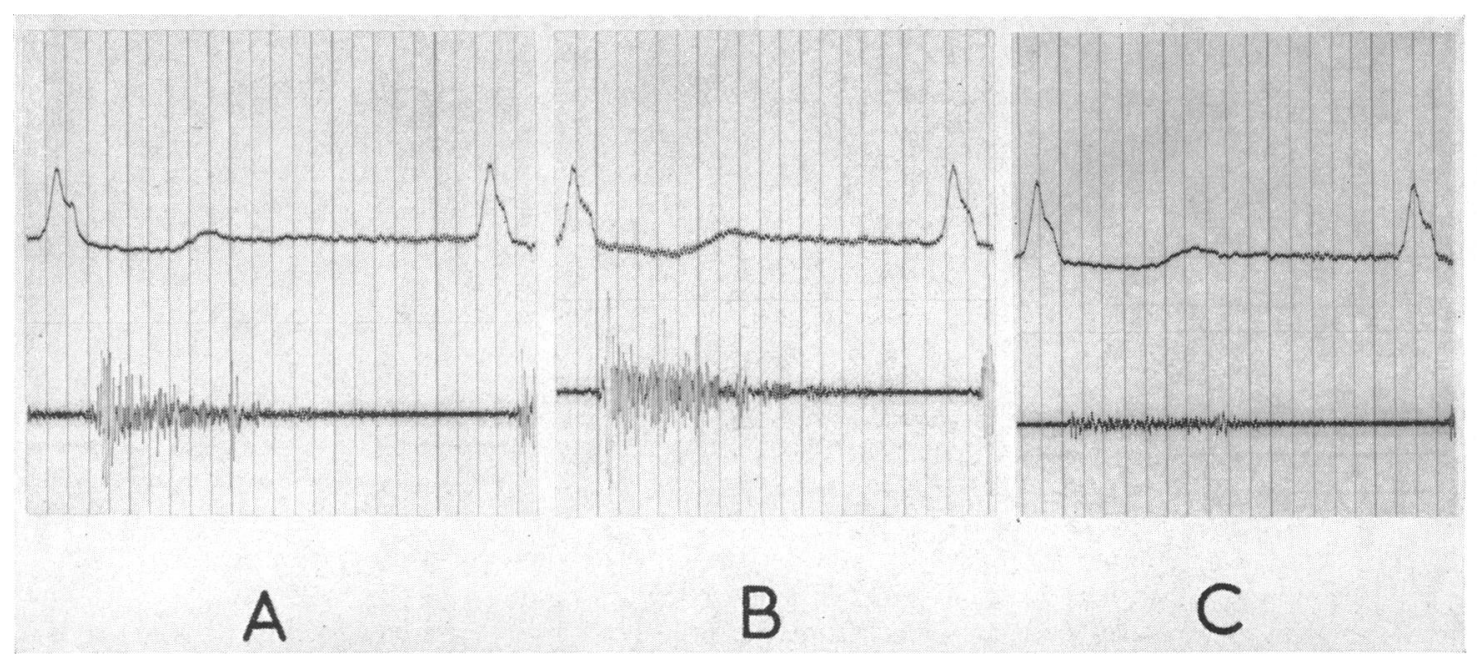

FIG. 1.-Phonocardiogram in cor pulmonale with tricuspid incompetence (Case B.McC.). (A) Over xiphisternum. (B) 1 inch below and 2 inches to the left over the liver. (C) 1 inch above and to the right of the xiphisternum. Upper recording-electrocardiogram. Lower recording-phonocardiogram. 
In rheumatic heart disease, tricuspid incompetence usually accompanied mitral incompetence in this series and in 4 of the 7 patients observed the radiation corresponded to that usually described, being best heard over the xiphisternum and radiating upwards, either to the right or left (Table II).

TABLE II

The Site of the Murmur and Radiation in Chronic Rheumatic Carditis

\begin{tabular}{l|l|l|c}
\hline \multicolumn{1}{c|}{ Name } & Diagnosis & Loudest area & Next loudest \\
\hline F.H. & M.S., M.I., T.I. & Xiphisternum & $\mathbf{U}_{1} \mathbf{L}_{1}$ \\
N.W. & M.S., M.I., T.I. & Xiphisternum & $\mathbf{U}_{1} \mathbf{R}_{2}$ \\
I.C. & M.S., M.I., T.I. & Xiphisternum & $\mathbf{U}_{1} \mathbf{L}_{1}$ \\
A.M. & M.S., M.I., T.I. & Xiphisternum & $\mathbf{U}_{1} \mathbf{R}_{1}$ \\
F.S. & M.S., M.I., T.I. & Xiphisternum & U.L.=D.L. \\
W.B. (5/1/59) & M.S., M.I., T.I. & D.L. & Xiphisternum \\
W.B. (26/1/59) & M.S., M.I., T.I. & Xiphisternum & D.L. \\
N.B. & M.S., T.I. & D $_{1} \mathbf{L}_{2}$ & Xiphisternum \\
\hline
\end{tabular}

M.S. =mitral stenosis. $\quad$ M.I. $=$ mitral incompetence. $\quad$ T.I. $=$ tricuspid incompetence.

In one patient (F.S.) the murmur was equally well heard above the xiphisternum and over the liver to the left and below the diaphragm. In another (W.B.) the radiation resembled that seen in patients with emphysema and cor pulmonale while in the last patient, on one occasion the murmur was best heard below the diaphragm and to the left and in another at the xiphisternum. Clinical examination in these three patients suggested that all suffered from emphysema in addition to rheumatic heart disease.

\section{DISCUSSION}

The distribution of the murmurs found in these patients together with the physical signs suggest that the radiation of the murmur of tricuspid incompetence below the diaphragm is related to the presence of emphysema. In this condition the lungs become enlarged and billowy, losing their normal elasticity, the liver becomes depressed, and the area of cardiac dullness is absent. It was at first considered possible that the unusual distribution of the murmur was apparent and due not to radiation through the liver substance, but to depression of the heart itself. Physical examination including percussion of liver dullness and radioscopy, however, revealed that this was not the case and that the murmur was in fact audible over the liver substance. Another possibility was that the murmur was not that of tricuspid incompetence but due to increased flow of blood through liver vessels as a result of reflux into the atrium during ventricular systole. This also seemed unlikely since the phenomenon was confined to patients with emphysema and the phonocardiographic character of the murmur in the xiphisternal area and the liver was similar. It seemed probable that the vibrations of the murmur were being transmitted directly through the liver substance. Observations were accordingly extended to a number of patients with mitral incompetence and it was found that the systolic murmur audible at the apex, as well as radiating to the axilla, could commonly be heard clearly over the liver substance. The point of maximal intensity over the liver, however, was close to the apex and not in the free edges of the liver as had been found in tricuspid incompetence. The reason for the unusual radiation in emphysema is likely to be a combination of the diminished area of the heart in contact with the sternum due to an increase in the bulk of the lungs together perhaps with a firmer application of the heart to the liver from the same cause.

\section{SUMMARY}

The site of maximal intensity and radiation of the murmur of tricuspid incompetence has been recorded phonocardiographically in patients suffering from emphysema and from chronic rheumatic heart disease. In chronic rheumatic heart disease the site of maximal intensity of the murmur is 
usually over the xiphisternum, the murmur radiating upwards to the right or left. In patients with emphysema and with cor pulmonale or rheumatic heart disease, the site of maximal intensity of the murmur is commonly over the free edge of the liver to the right or left and at the xiphisternum the murmur is less well heard. It is suggested that the usual radiation in emphysema is the result of the diminution in the area of cardiac dullness and possibly a firmer application of the heart to the liver as a result of the increased bulk of the lungs.

\section{REFERENCES}

Bramwell, B. (1884). Diseases of the Heart and Thoracic Aorta. Pentland, Edinburgh.

Broadbent, J. F. H. (1897). Heart Disease with Special Reference to Prognosis and Treatment. Baillière, Tindal and Cox, London.

Gibson, G. A. (1898). Diseases of the Heart and Aorta. Pentland, Edinburgh.

Levine, S. A., and Harvey, P. W. (1959). Clinical Auscultation of the Heart. Saunders, Philadelphia and London.

Mackenzie, J. (1913). Diseases of the Heart. Frowde, Oxford.

Muller, O., and Shillingford, J. (1954). Brit. Heart J., 16, 195.

Stokes, W. (1854). Diseases of the Heart and the Aorta. Hodges and Smith, Dublin.

Stuart-Harris, C. H., Twidle, R. S. H., and Clifton, M. (1959). Brit. med. J., 2, 201.

White, P. D. (1944). Heart Disease. Macmillan, New York.

Wood, P. (1956). Diseases of the Heart and Circulation. Eyre and Spottiswoode, London. 